This item was submitted to Loughborough's Research Repository by the author.

Items in Figshare are protected by copyright, with all rights reserved, unless otherwise indicated.

\title{
Physical activity advocacy in the UK: a multiple streams analysis of a hybrid policy issue
}

PLEASE CITE THE PUBLISHED VERSION

http://dx.doi.org/10.1080/02614367.2017.1285957

\section{PUBLISHER}

(c) Taylor \& Francis

\section{VERSION}

AM (Accepted Manuscript)

\section{PUBLISHER STATEMENT}

This work is made available according to the conditions of the Creative Commons Attribution-NonCommercialNoDerivatives 4.0 International (CC BY-NC-ND 4.0) licence. Full details of this licence are available at: https://creativecommons.org/licenses/by-nc-nd/4.0/

\section{LICENCE}

CC BY-NC-ND 4.0

\section{REPOSITORY RECORD}

Piggin, Joe, and Louise Hart. 2017. "Physical Activity Advocacy in the UK: A Multiple Streams Analysis of a Hybrid Policy Issue”. Loughborough University. https://hdl.handle.net/2134/24057. 


\section{A multiple streams analysis of physical activity advocacy}

Physical activity advocacy in the UK: A multiple streams analysis of a hybrid policy issue

Abstract:

Physical activity is increasingly being defined as a major, complex, multisector issue. In order to understand more about how this expanded conception of physical activity is being factored into public policy, this article applies the multiple streams theory of policy change to examine the United Kingdom (UK) physical activity domain. Participant observation, policy analysis and media analysis are combined to examine the ways in which the political context, problem framing and policy solutions were brought together by a range of policy entrepreneurs. The study pays particular attention to how one lobby effort in the UK, the All Party Committee on Physical Activity (APCPA) attempted to elevate physical activity to a higher level of importance. The findings show how a hybrid form of organisation made up of traditional interest groups, corporations and government insiders, has successfully decreased ambiguity about physical activity and increased both official and public attention about the issue. The article suggests that while the multifarious benefits of physical activity and the diverse range of organisations involved have contributed to momentum towards policy change, these factors may also inhibit physical activity from remaining high on the policy agenda. Suggestions are offered for policy practices at a national level. 


\section{A multiple streams analysis of physical activity advocacy}

\section{INTRODUCTION}

Low population levels of physical activity are a growing concern for public health promoters. Along with traditional connotations with physical fitness, advocates are increasingly connecting physical activity with ideas about more cohesive communities, more environmentally friendly cities and more productive and profitable companies (cf. Kohl, 2012; Nike et al, 2012). Schools, workplaces, communities, cities and countries are all increasingly being suggested as sites in which to intervene to promote physical activity. The impetus towards expanding the values of physical activity has advanced concurrently with epidemiological evidence outlining the various health costs of physical inactivity. The physical inactivity pandemic is claimed to be responsible for more than $5 \cdot 3 \%$ of the 57 million deaths that occurred worldwide in 2008 (Lee et al., 2012). At the same time as epidemiological evidence is growing, there is also prominent rhetoric about the perceived inadequacy of current interventions and the need for a 'revolution' in approaches to physical activity promotion (Das and Horton, 2012). Recently academics have pronounced 'more of the same (in terms of research, policy and practice) will not be enough' to change the situation (Hallal et al. 2012, p.191). In low-income countries, it has been argued that knowledge about 'evidence-based strategies for increasing physical activity is poor' (Hallal et al. 2012, p. 191). The problem has been traditionally framed as populations not meeting physical activity guidelines of a certain number of minutes of moderately intense physical activity per week (Pate et al., 2002).

In the United Kingdom (UK) specifically, high population-wide physical inactivity rates have been identified as a serious health concern with the problem often being linked to years of life lost and economic costs. In 2014, four major policy and lobby documents about physical activity were published. These included Turning 
the Tide of Inactivity by UK Active, a lobby group representing over 3,000 active lifestyle organisations (January 2014), Moving More, Living More: The Physical Activity Olympic and Paralympic Legacy for the Nation, co-authored by the UK Government, the Mayor of London and Lord Sebastian Coe (February 2014a), Tackling Physical Inactivity: A Co-ordinated Approach, produced by an informal group of politicians (April 2014) and Everybody Active, Every Day: An Evidencebased Approach to Physical Activity, the first of various documents produced by Public Health England, who are sponsored by the Department of Health to protect and improve health (October 2014a). These documents aimed to increase awareness about the importance of physical activity, and all were written by organisations perceived as having a legitimate interest in population health.

\begin{tabular}{|l|l|l|l|l|}
\hline Title & $\begin{array}{l}\text { Turning The Tide } \\
\text { of Physical } \\
\text { Inactivity }\end{array}$ & $\begin{array}{l}\text { Moving More, } \\
\text { Living More - The } \\
\text { Physical Activity } \\
\text { Olympic and } \\
\text { Paralympic } \\
\text { Legacy for the } \\
\text { Nation }\end{array}$ & $\begin{array}{l}\text { Tacking Physical } \\
\text { Activity - A Co- } \\
\text { ordinated Approach }\end{array}$ & $\begin{array}{l}\text { Everybody Active, } \\
\text { Every day - An } \\
\text { Evidence-Based } \\
\text { Approach to } \\
\text { Physical Activity }\end{array}$ \\
\hline Status & Lobby document & Govt. policy & Lobby document & Govt. policy \\
\hline $\begin{array}{l}\text { Main } \\
\text { Authors }\end{array}$ & UK Active & $\begin{array}{l}\text { DOH, Cabinet } \\
\text { Office, DCMS, } \\
\text { D.F.Education, } \\
\text { D.F.Transport }\end{array}$ & $\begin{array}{l}\text { All Party } \\
\text { Commission on } \\
\text { Physical Activity, All } \\
\text { Party group }\end{array}$ & $\begin{array}{l}\text { Public Health } \\
\text { England }\end{array}$ \\
\hline $\begin{array}{l}\text { Main } \\
\text { Ideas: }\end{array}$ & $\begin{array}{l}\text { Establishes the } \\
\text { scale of the } \\
\text { physical inactivity } \\
\text { epidemic in the } \\
\text { UK. }\end{array}$ & $\begin{array}{l}\text { A commitment to } \\
\text { promote physical } \\
\text { activity across the } \\
\text { country's } \\
\text { population }\end{array}$ & $\begin{array}{l}\text { Establish an over- } \\
\text { arching National } \\
\text { Plan of Action to } \\
\text { tackle declining } \\
\text { levels of physical } \\
\text { activity. }\end{array}$ & $\begin{array}{l}\text { A plan to engage } \\
\text { with many different } \\
\text { sectors and } \\
\text { employers to make } \\
\text { the case for much } \\
\text { more physical } \\
\text { activity, every day. }\end{array}$ \\
& $\begin{array}{l}\text { Calls on govt to } \\
\text { develop and } \\
\text { deliver a cross- } \\
\text { party, cross- } \\
\text { government } \\
\text { and cross-sector } \\
\text { national strategy }\end{array}$ & $\begin{array}{l}\text { Increase PA by } \\
\text { involving partners } \\
\text { across all sectors } \\
\text { and levels working } \\
\text { together. }\end{array}$ & $\begin{array}{l}\text { Have cross party } \\
\text { and cross sector } \\
\text { agreement. }\end{array}$ & \\
\hline
\end{tabular}

Table 1: 2014 UK Physical Activity Publications 


\section{A multiple streams analysis of physical activity advocacy}

A multiple streams theoretical approach is utilised for this research. While the multiple streams framework has been used in other health areas as diverse as Canadian national health insurance policy (Blankenau, 2001), at a local level in a low income country - Burkina Faso (Riddi, 2009) and Swedish public health policy (Guldbrandsson and Fossum, 2009), this is the first study to apply the framework to the growing global, multi-sectorial, multi-faceted policy domain of physical activity policy.

\section{THEORETICAL FRAMEWORK}

This article does not conceive of physical activity policy as simply emerging from a rational decision making process. Rather, it considers the emergence of a policy issue as both actively constructed and influenced by a range of forces which might be outside of policy makers' control (Kingdon, 1985). A multiple streams analysis is considered a useful way of examining such factors. Kingdon (1985) developed the 'multiple streams framework' to explain why some issues are focused upon as policy concerns and some are not. The theory assumes that policy is not constructed through stable conditions by rational actors but rather in a milieu with a high level of ambiguity, complexity and randomness. It is an approach which in principle accommodates the political nature of health promotion. The theory employs three 'streams' of problems, policies and politics to explain policy change. It is the combination of these, Kingdon suggests, which allows for policy change to occur. The three streams are always in flux and not necessarily aligned, which is why some social problems do not gain the necessary momentum to have resources (such as legislation or funding) devoted to them. The streams are briefly outlined here. 


\section{A multiple streams analysis of physical activity advocacy}

First, the problem stream consists of those "conditions" which policy makers have chosen to interpret as problems. How officials learn about a topic (such as physical in/activity), and the ways in which a topic is defined as a problem are the focus. Indicators, dramatic events, crises, and feedback from existing policy inform stakeholders about an issue. For example, ongoing news reports about childhood obesity statistics often serve as a proxy for a population not being active enough. To similar effect, media images of obese (and supposedly unhealthy) people are often used to personify a health crisis. Second, the policy stream involves various ideas and solutions which are produced by experts in 'policy communities'. For example, in the realm of school sport, ideas might include the belief that physical education is a crucial part of the school curriculum, or that privatization improves the quality of sports services (Houlihan and Green, 2006). Third, the politics stream revolves around 'macro-political' elements which exist in a given milieu. For instance, the public mood and changes in the ruling political parties might contribute to an issue gaining prominence.

With this brief overview of the three steams in mind, one further important element is coupling. Kingdon notes that there are 'fleeting opportunities for advocates of proposals to push their pet solutions, or to push attention to their special problems' (p. 165). An important part of an issue gaining traction is having successful "policy entrepreneurs" - people who can connect these often disparate streams in order for an issue to gain traction in an official sphere. The multiple streams framework posits that the ability of policy entrepreneurs to synergistically link previously isolated streams will significantly enhance the likelihood of an issue gaining policy attention. 


\section{A multiple streams analysis of physical activity advocacy}

The multiple streams framework was chosen for two reasons. First, it is a respected, traditional form of process analysis (Walt et al. 2008). Second, we realised it was important to test its robustness for a policy problem that involves a wide array of actors, sectors and possible consequences. No model can account for all aspects of the policy process. One benefit of this model is that it accounts for agents involved in policy. Another is that, like much sport policy, there is a lack of systemic embeddedness of physical activity in national policy systems, and so the role of policy entrepreneurs can be focused upon (Houlihan, 2005). Prior to this current research it was observed that groups with vested interests had been making concerted efforts to give physical activity a solid foundation, such as Nike (see Piggin, 2014) and UK Active, an industry lobby group. Therefore the apparent political machinations involved in the physical activity milieu meant that a multiple streams lens would be useful.

We appreciate there are limitations to the model as well. Houlihan notes "the preoccupation with agenda setting results in the relative neglect of other stages of the policy process, especially implementation" (2005, p. 173). However, we believe that the benefit of investigating the emergent policy process is a fundamentally essential element, as this is when core ideas about the problem are argued about and cemented in policy discourse. This is especially important because of the range of (possibly) competing interests and actors involved.

This study therefore examines how physical activity is being framed as a major policy concern in the UK. While the study focuses on the UK, it is apparent that similar physical activity advocacy is taking place in many other developed countries, including Canada (Faulkner et al. 2011), the USA, Australia (Shilton, 2006) 


\section{A multiple streams analysis of physical activity advocacy}

New Zealand (Richards et al., 2011), and various countries in Europe (Kahlmeier et al, 2014).

\section{METHOD}

The multiple streams approach necessitates gathering data from a wide range of sites. The net in this case was purposefully cast wide due to what Lang and Rayner (2006) describe as 'policy cacophony', whereby numerous interest groups compete to further their diverse agendas. A range of macro, meso and micro aspects of agenda setting were analysed. At a macro (politics) level, the two authors attempted to identify the dominant political issues and concerns to situate the analysis within its socio-political and socio-economic context. This analysis particularly took into account government statements about the need for budget cuts in a range of public services, which might impact on the provision of state-funded physical activity programmes and facilities. Further, mainstream media reports were critically analysed between 2012 and 2014 . This period was chosen because it was considered to be a time of significant media interest in physical activity, due in part because of the supposed Olympic legacy of inspiring people to become physically active, as well as emerging health literature emphasising the detrimental consequences of insufficient physical activity. While various newspapers, television and web-based sources were observed and monitored by the researchers, three in particular were used to contextualise the "politics of the day" and examine discussion about physical activity and health policy. These included British Broadcasting Corporation (BBC) news reports and nation-wide newspapers including The Times and The Independent. Keyword searches included the terms "physical activity", "activity", "policy", "obesity", "physical education", "sport policy", "Sport England" and 


\section{A multiple streams analysis of physical activity advocacy}

"Public Health England". While this approach allowed for a wide breadth of analysis, we acknowledge at times this resulted in trading off against depth of analysis at the macro level.

The major focus of this study occurred at a meso level. The policy stream was analysed through a specific focus on one policy change initiative: the All Party Commission on Physical Activity (APCPA) which published Tackling Physical Inactivity: A Co-ordinated Approach (2014). The APCPA was established in late 2013 as an All Party Parliamentary Group, which are

'informal cross-party groups that have no official status within

Parliament. They are run by and for Members of the Commons and Lords, though many involve individuals and organisations from outside Parliament in their administration and activities' (UK Government, 2014b).

Thus it would be more appropriately described as a lobby or interest group. The APCPA was chaired by three Members of Parliament, one from each of the three largest political parties at the time, with another 3 MPs acting as Commissioners. The APCPA website stated it "was set up is in response to the overwhelming evidence in the Designed to Move report and the need for action to end the physical inactivity epidemic in the UK" (APCPA, 2013b). Regarding low levels of population physical activity, the APCPA aimed 'to address this urgent issue and make direct, policy-based recommendations to tackle this crisis .... [a] novel approach is vital so that we can look for the first time at the whole, rather than the individual strands working in silo ...' (APCPA, 2013).

This case study was chosen in order to examine how the lobbying process would manifest and unfold over a period of five months from November 2013 to April 2014. Numerous factors made this a compelling site of the policy process in action. 


\section{A multiple streams analysis of physical activity advocacy}

First the case involved many of the prominent organisations and stakeholders in the physical activity realm. The wide array of stakeholders also provided useful insight through both oral hearings and written submissions. The APCPA oral hearings involved statements from and discussions with state organisations such as Sport England and Public Health England and charities such as the British Heart Foundation. Private interest groups were also involved. For example, Public Health England would praise Nike for driving the Designed to Move coalition that instigated and supported the All-Party Commission (2014b). Second, the APCPA provided 'evidence sessions', most of which were open to the public. Third, the researchers assumed the APCPA would generate rich primary data about physical activity policy solutions, through in-person evidence sessions, media reporting and social media interaction. Acknowledged limitations of the case included the fact some of the meetings were inaccessible due to being closed to the public, and that it was not possible to examine the machinations involved in the construction of the APCPA 'behind the scenes'. As Abma (2006) notes, evaluating policy needs to include an appreciation of power relations, ambiguity and a plurality of interests in policy settings.

Various aspects of the APCPA were examined systematically. First, the APCPA website was used to determine how the problem was framed, and also as a source to examine the written evidence to the APCPA. The researchers attended and wrote field notes which were later transcribed at three of the four public evidence sessions (on education, health and sport) and transcribed the discussions between the APCPA members and various "evidence givers". Written submissions to the APCPA were also examined. These submissions were emailed to the APCPA by interested individuals and organisations, ranging from local residents, to academics, 


\section{A multiple streams analysis of physical activity advocacy}

local councils and organisations involved with physical activity. These transcripts and submissions were then coded into themes for analysis. These themes were established by connecting the data with various elements of concern in the multiple streams framework, including evidence about dramatic events, feedback from existing policies, the causes of the problem, proposed solutions, and the different types of statistics and narratives used to support claims. While an apparent limitation of the data collection method was the inability to access all of the APCPA's hearings (since some were not open to the public), it is acknowledged that undertaking policy research will inevitably be constrained by limited access to meetings and conversations between lobbyists and policy insiders. The final report named 'Tackling Physical Inactivity - A Coordinated Approach' was also critically read.

Publicity material from interest groups and policy communities was also examined. This included news media statements, advertisements, organisational websites and social media sources. At a micro level, social media interactions between various individuals involved in the issue were used as valuable data sources. For this the researchers relied on the designated twitter hashtag of the APCPA, \#activitycommission which was attached to hundreds of tweets over the 5 month period. The data collection and analysis was approached in an iterative manner, whereby themes were established, developed and shaped throughout the research process. The prominent themes which emerged about physical activity policy and which were connected with the aforementioned elements of concern included ideas about health, risk, crisis, investment, Olympic legacy, sport versus physical activity, cross sector connections, best practice (inside and outside the UK), radical and incremental change. These elements considered most important were then crafted into the following analysis. 


\section{A multiple streams analysis of physical activity advocacy}

\section{RESULTS}

\section{The problem stream in UK physical activity policy}

The problem stream involves those conditions which policy makers have chosen to interpret as problems. The legitimacy of physical activity as a policy concern relies on associating it with a number of other social outcomes, as distinct from promoting activity simply as an end by itself. That is, increasing an individual's daily calorie expenditure through muscular exertion is not persuasive as a policy aim. Activity is therefore linked with a range of other domains, including, the economy, environment, education, health and social inclusion aims. As such, the issue of physical inactivity in the UK is being supported by a plethora of data about the benefits of activity and costs of inactivity around which knowledge is framed. All the documents from the APCPA, UK Active, Public Health England and the UK Government emphasised that something needed to be done. The dominant conditions which have made physical activity ripe for policy attention include the following indicators, event and feedback.

\section{Indicators}

While most observers would agree that the 2012 Olympic Games were a positive showcase for Great Britain and a very successful event for athletes of the host nation, the mass participation Olympic legacy goals have been equivocal. For instance, before the Olympic Games even started, Sport England (the state funded body which provides services and funding to sport organisations) acknowledged the original target of having one million more people playing sport three times per week measured by the Sport England's Active People Survey, would not be achieved 


\section{A multiple streams analysis of physical activity advocacy}

(Peck, 2012). While Sport England have at various times produced press releases proclaiming that more people are playing sport (see Sport England, 2014), there are also confounding data. In 2013, the Independent newspaper included the headline 'Significantly fewer people now playing sport regularly than before last year's Olympic Games' (Scott-Elliott, 2013).

\section{Crisis / Feedback on Existing Policy}

Physical inactivity is increasingly framed as a pandemic in its own right, which is a change in health literature which has traditionally regarded it as a contributor to obesity. While physical inactivity is at times discussed as part of a complex causal chain affecting health, there were also many claims that physical inactivity causes death. For example, 'Physical inactivity is the fourth leading cause of death worldwide' (Kohl et al., 2012, p. 294). With such stark data, physical activity researchers are playing a role in elevating it on the health agenda. The Designed to Move lobby document (Nike et al., 2012) also used ominous language to describe the situation: 'most alarming is the fact that the problem, its costs and its consequences are passed forward across generations, creating a cycle of poor physical and emotional health, and tragically wasted human potential' (p. 2), and detailed the various "human costs and economic consequences" (p. 8-9) for countries around the world. In a call to action, the UK Government (2014a) explained that ' $28.5 \%$ of adults fail to achieve even 30 minutes of physical activity over seven days' (p. 7).

There is also no shortage of data available which has contributed to the perception of pressing need for policy action. Regarding feedback from existing policy, there is a growing awareness of physical activity guidelines for different 


\section{A multiple streams analysis of physical activity advocacy}

populations (children, adults, older adults). An example of how this data is turned into policy comes from Moving More, Living More:

to have a year on year increase in the number of adults doing 150 minutes of exercise per week (in bouts of 10 minutes or more) and a year on year decrease in those who are inactive, defined as doing less than 30 minutes of exercise per week (in bouts of 10 minutes or more). (2014a, p. 5)

Beyond these various official guidelines of "at least" a certain number of minutes per week, physical activity appears to be framed as wholly positive (as evidenced from the various titles of the documents) and inactivity as wholly negative. The resounding idea throughout policy is that more is needed.

Another important source of data is ongoing obesity statistics. The detrimental health effects of obesity have been propagated over the last two decades in the UK, and mainstream media regularly devote articles to the ongoing issue. In January 2014, a BBC article entitled 'Obesity crisis: Future projections underestimated' included a professor's claim that 'the crisis could get even worse than the 'doomsday scenario' already set out' (BBC, 2014). Of course, what is worse than a doomsday is difficult to comprehend, though it does illustrate the alarmist rhetoric which works in tandem with data.

According to the multiple streams theory (Kingdon, 1985), these aforementioned aspects of the problem stream must interact with the values and beliefs of policy officials in order to contribute to policy change. Aside from typical appeals to health and wellbeing a number of values and beliefs were apparent in the various lobby documents. In particular, ideas about nature and tradition were prominent. For example, the APCPA appealed to ideas about what is 'natural' and stated that 'the human body was designed to move' (2013, italics added). These 


\section{A multiple streams analysis of physical activity advocacy}

ideas also apparently informed the evidence givers to the APCPA. Evidence giver Paula Radcliffe implored the APCPA that a key message should be to 'inspire what is naturally there in a child' and not to ignore children who were 'naturally competitive' (Radcliffe, 2014, italics added) 'Tradition' also informed the physical activity lobby efforts. Evocations of tradition were present throughout the APCPA oral evidence sessions, with frequent reminiscing about what life used to be like. Epidemiological evidence is used to define people in the past as being more physically active than now.

\section{The policy stream in UK physical activity}

This aspect of agenda setting focuses on the various ideas and solutions which are produced by experts in 'policy communities'. The multiple streams theory distinguishes between interest groups and policy communities. Interest groups often include organisations without formal government positions, such as business and industry, professional associations, labour groups, and government officials as lobbyists. Policy communities 'are composed of specialists in a given policy area .... [and] are scattered both inside and outside of government' (Kingdon, 1985, p. 117).

For a topic such as population physical activity, the communities involved are indeed numerous, and include academics, researchers, education and health groups, as well as councils, charities and sports groups. The enlargement of the physical inactivity problem also involves groups ranging from transport agencies (such as Transport for Greater Manchester and the Passenger Transport Executive Group who submitted evidence to the APCPA) to architecture organisations (such as the Royal Institute of British Architects which gave oral evidence to the APCPA) (2014). It became apparent that in this case study there was also much overlap between 


\section{A multiple streams analysis of physical activity advocacy}

interest groups and policy communities to the extent that the APCPA could best be described as a hybrid interest group / policy community.

It was apparent there was intense interaction between the physical activity community in the organisation of the APCPA, to the extent that this was a combination of interest groups and policy communities. This hybrid form of organisation was consciously constructed to appear official. This was accomplished in various ways, including naming itself as a seemingly official 'Commission' (as opposed to the more usual term 'Group'), taking place in the Palace of Westminster (on the premises of the UK Government), being organised by six Members of Parliament and a 'non-party political crossbench peer', and emphasizing rationality through evidence gathering. Although these factors added to the APCPA's perceived authority, the APCPA was actually part of an 'all party group' (APG). APGs do not have official status within Parliament (UK Government, 2014c). Rather, APGs would more appropriately be termed as interest or pressure groups (BBC, 2011). The APCPA sat under the auspices of the 'APG Sport' and according to APCPA website 'The Co-Chairs and Commissioners are supported in this work by the Designed to Move Champions ...' (APCPA, 2013). This point is important, since it became clear that some of the groups giving 'evidence' to the APCPA were also already supporting it. For example, Nike, the lead author of the aforementioned Designed To Move, had a spokesperson give evidence.

The multiple streams theory notes that the communication channels between interest groups are extraordinarily open. While this comment was made in 1984 , it is certainly even more evident in this century, with the popularity of social media. The APCPA encouraged discussion via the twitter hashtag \#activitycommission. Before, during and after the oral evidence sessions in late 2013 and early 2014, there was 


\section{A multiple streams analysis of physical activity advocacy}

much tweeting about some of the main claims made during the sessions, and many tweets encouraged the APCPA to make powerful recommendations. For instance: Mandy Ayres@Frankly66.Feb 11 \#activitycommission need to work cross department (Ayres, 2014a)

Philip Insall@PhilipInsallFeb 10 Two in three are overweight, inactivity is costing billions. Let's get that \#activitycommission report out and start changing things (Insall, 2014)

The line between interest groups and policy communities therefore became blurred. In the case of the APCPA, by virtue of the fact that there was a call for evidence essentially turned many interest groups into policy communities. The APCPA explicitly asked 'What fundamental policy changes need to be made to increase the levels of physical activity across the UK?' (APCPA, 2013). Of the over 200 oral and written submissions, many were from representatives of larger groups such as the Associations of School and College Leaders, Birmingham City Council, and the Federation of Sports and Play Associations.

Kingdon also notes that communities also have their interactions with each other in common. There were many instances which indicated the closeness of the policy communities in the physical activity domain. For example, at the beginning of the 'sport' oral evidence session, chair Baroness Tanni Grey-Thompson remarked that 'It's funny sitting here in front of you all when I know pretty much all the faces and everyone here' (Grey-Thompson, 2014). Similarly, a tweet from the chair of the Sport and Recreation Alliance read 'The \#activitycommission also be welcoming @mikediaper @tim_woodhouse - regular evidence givers!' (Reed, 2014). This highlights the blurring between insider and outsider in the physical activity realm. 


\section{A multiple streams analysis of physical activity advocacy}

Beyond the APCPA case study, there are both national and international policy communities contributing to physical activity discourse in the UK. Public Health England, Sport England, UKActive, Sustrans (for sustainable transport), and various charities such as the British Heart Foundation all contribute to the dominant public discourse about physical activity. Supranational organisations such as the World Health Organisation and the United Nations also set various guidelines and principles about health, such as the European Physical Activity Strategy (WHO, 2016). Further, a number of advocacy coalitions including the Designed To Move lobby group and others (more indirectly including the Lancet Physical Activity Series Working Group and The International Society for Physical Activity and Health, http://www.ispah.org) have been influential in adding legitimacy to physical activity as a health concern.

Ideas - promoted and demoted

A multiple streams approach considers how ideas are brought to life so they can be seen as solutions. Throughout the lobbying process, some solutions gather strength and legitimacy, while others weaken and disappear from the discourse. The APCPA, Public Health England, and UKActive chose and framed which ideas to present as solutions. To illustrate, the potential solutions offered to the APCPA by oral evidence givers included a vast array of ideas such as 'Make young people feel part of a family', 'Street closure (to cars) is important for physical activity', 'Use sportsmen and women for inspiration', ‘Emphasise physical literacy', 'Don't mention sport at all in physical activity promotion' (Oral evidence, 2014). These examples from the oral evidence sessions from a range of evidence givers illustrate the 


\section{A multiple streams analysis of physical activity advocacy}

diversity of possible policy actions, which ranged from novel ideas of the speaker to best practice examples taken from other communities or countries.

It was apparent the dominant concern of the APCPA was children and young people. This was also apparent in the final report of the APCPA, which featured only photographs of children being active. This was commented on by one physical activity academic: "All-party report on physical activity: 12 photos, all on children and 8 on sport. Adults, non-sport PA not important? \#activitycommission" (Biddle, 2014). Since a significant majority of the discussions were given to children and young people, there was little (and at times no) emphasis from various oral evidence givers to discuss the concerns of employees and workplaces (for example).

\section{The politics stream in UK physical activity}

In the multiple streams framework, the political stream includes aspects such as the public mood, pressure group campaigns and ideological distributions in parliament (Kingdon, 1985). Generally, the UK has experienced a difficult period economically since 2008. Increased unemployment, a weaker currency value and periods of recession have all contributed to what could be described as a dampening of optimism in the public mood. A period of governmental austerity measures began in 2010 with the prospect of continuing late into the decade. While economically, there was little to be inspirational about for many, it is clear that appeals to the public ‘spirit' framed the Moving More, Living More campaign. Prime Minister David Cameron reminded readers of the memories from the Olympic Games to assist in mobilising the nation:

'The country was captured by the spirit of the 2012 Games, inspired by our sporting heroes and their many achievements. We now need to build on this, 


\section{A multiple streams analysis of physical activity advocacy}

creating a nation that's physically active and improving their health for the long term' (Cameron, 2014).

While the three main political parties in the UK at the time of writing (Conservative, Labour and Liberal Democrats) competed on many issues, arguments of Olympic Games legacy and physical activity have been framed as 'all party' or bipartisan issues. While sporting concerns do not usually cause major arguments in government spheres, all the parties were proud of the successful hosting of the Olympic Games.

There is both certainty and uncertainty present in the physical activity policy rhetoric. Three events in particular at the end of 2013 and beginning of 2014 highlight unity about the idea that policy change is needed. One was the establishment of the APCPA in 2013 and its published report in April 2014. Similarly, in February 2014, the UK Government published Moving More, Living More, a new discussion document attending to the Olympic legacy values regarding physical activity promotion. Moving More, Living More, boldly states (in bold text) that 'never again will we allow physical activity to occupy a silo in any one department' (UK Government, 2014a, p. 5). Also, in the same month an interest group called UKActive published a document called Turning the Tide of Inactivity (2014). UKActive represents over 3000 members consisting of organisations such as fitness centres and leisure providers in the UK. Their document claims that 'urgent action is required that challenges central government, local authorities and the activity sector to get more people, more active, more often' (Stalker, 2014, p. 4). These three distinct efforts to stimulate policy change indicate the broad consensus regarding the need for a multi-sector, co-ordinated view of physical activity promotion. 


\section{A multiple streams analysis of physical activity advocacy}

\section{The importance of policy entrepreneurs (and Nike)}

Policy entrepreneurs are an important part of the agenda change process since they help to bring the often disconnected streams together. Policy entrepreneurs tend to be people with a claim to be heard, who have political connections which will be potentially useful, and who are persistent. The multiple streams approach notes that policy entrepreneurs must be prepared with 'their special problem well documented, lest the opportunity pass them by' (Kingdon, 1985, p. 173). In the case of the physical activity policy arena, it is apparent that there have been a number of individuals and groups who could be described as policy entrepreneurs. One of the most prominent has been Lord Sebastian Coe - The former British Olympic champion, former Member of Parliament (MP) and the chairperson of the London Olympic Games Organising Committee. His status as a leader for sport promotion is perhaps unparalleled in the UK. His supporting comments legitimize the value of a physical activity lobby and his endorsements feature on the APCPA website, and in the Turning the Tide on Physical Activity and Moving More, Living More documents. Coe also delivered a message via video link to the launch event of Everybody Active, Every Day, making him an omnipresent spokesperson in every major UK physical activity lobby effort in 2014.

With a reputation similar to Lord Coe, Baroness Tanni Grey-Thompson has won numerous Paralympic gold medals over many years. Along with a role as a director of UK Athletics and a member of the board of the London Marathon, she has been involved with committees on Environment, Corporate and Planning and Surface Transport and Safety. Out of the seven co-chairs and Commissioners of the APCPA, Grey-Thomson was the only one who was not an MP. She possessed 


\section{A multiple streams analysis of physical activity advocacy}

significant social capital in physical activity and sport which was evident in her session that she chaired.

To expand on the traditional conception of a policy entrepreneur as an individual person, it was apparent that the Nike corporation has been an enthusiastic corporate 'person' from 2012 to 2014. As the lead author of Designed To Move and a key supporter of the APCPA, Nike successfully joined the problem stream with the policy stream (by mobilising various interest groups in order to establish the APCPA). In explaining Nike's reasons for becoming involved in physical activity lobbying, spokesperson Mandy Ayres remarked that Nike had been 'hearing more and more that physical activity is decreasing'. Following 'conversations', Ayres stated that the conclusion was that 'a global community concerned about physical activity' was needed (Ayres, 2014b). However, Nike did not proclaim to be an expert in the scientific domain. In response to a question regarding what could be measured differently, Ayres replied that a "group of experts need to come up with that." Nike's role therefore, as was mentioned elsewhere in Designed To Move documentation was to galvanise and align different sectors around a common goal. This was undoubtedly achieved, with the main ideas of Designed To Move featuring throughout the final APCPA report.

It is not only groups but also solutions that must be mobilised. Solutions need to be linked with policy communities. The emphasis on young people in both the APCPA's final report and the subsequent activity promotion campaign 'Move1Hour' (Move1hour, 2014a) which was endorsed on the APCPA website, demonstrate that while different groups are acknowledged in the APCPA report, the dominant ideas largely echo the Designed To Move lobby document from 2012 (Nike et al., 2012). Specifically a few pages in both Designed To Move and the APCPA report show 


\section{A multiple streams analysis of physical activity advocacy}

major similarities, to the extent that some phrases are virtually identical. The APCPA report used Nike's 'copyright' Human Capital Model, and the style, tone and solutions offered in the APCPA report are similar to Designed To Move. In one instance, the similarity is so great that an advertisement used in the Designed To Move campaign in 2012 was rebranded with the Move1Hour logo in 2014 (Move1Hour, 2014b). At the time of writing, the overwhelming focus throughout the Move1Hour campaign is on young people, also echoing the Designed To Move document.

Given that many of the Designed To Move Champions were both supporting the APCPA as well as providing evidence to it, it is perhaps not surprising that many of the ideas in Designed To Move are duplicated in the final APCPA report. However, it does highlight the ability of particular interest groups or organisations to frame the debate about the solutions to population physical inactivity in particular ways. These close links to the 'Move1Hour' campaign indicates hybridity of the APCPA as at once a pseudo-official evidence gathering group and a physical activity promoter with specific target groups in mind. It might also raise questions about how "revolutionary" and effective such an approach might be.

The multiple streams theory suggests that policy windows 'open infrequently, and do not stay open long' (Kingdon, 1985, p. 174). An intense period of lobbying took place in the first half of 2013 in order to stimulate the various interest groups. Mandy Ayres from Nike explained that around '70 experts' had been involved in the production of Designed To Move. By mobilising such a sizable group of interested parties, including a range of international and civil society organisations, Nike and the co-authors of Designed To Move effectively captured and disseminated the growing zeitgeist about physical inactivity. 


\section{A multiple streams analysis of physical activity advocacy}

\section{DISCUSSION}

It is important to beware of overly deterministic applications of the multiple streams framework. Simply because one context contains many of the same elements, it does not necessarily follow that a similar outcome will result. Kingdon notes that when a problem arises, solutions will flock to it. One possible outcome is that there might be so many alternatives that the momentum to achieve significant change collapses under its own weight, and that participants revert to more manageable issues. It is surely the case that for physical activity policy implementers working across a range of sectors, change will be difficult, and the solutions offered for each sector will probably not be of a 'one size fits all' nature. Further, the increasingly immense array of organisations in each sector required to change might well make 'revolutionary' change impossible.

The multiple streams framework attempts to explain policy change. While it does not offer a best practice method to elevate physical activity onto a state policy agenda, there are insights from this analysis that can be applied to other countries where physical activity is low on the policy agenda. One insight is that to encourage and mobilise policy entrepreneurs to align the various policy streams, advocates and stakeholders should consider which individuals would perform best as policy entrepreneurs. Houlihan and Green (2006) found that for the case study of school sport and physical education in England, the space for policy entrepreneurs was strong when only weak lobby groups existed. In the present study, it was apparent that there were both strong interest group lobbying and individual policy entrepreneurs at work. Another point to consider in other countries is that those involved should engage with the current momentum of some countries which are 


\section{A multiple streams analysis of physical activity advocacy}

more explicitly focusing on physical activity as a multi-sector issue. Further, rather than relying solely on evidence-based research, it is highly important for effective policy for health advocates to consider the political context to stimulate change. According to the multiple streams framework, chances of successful policy change (which is distinct from both consensus and successful policy implementation) will increase if the political context is taken into account.

Regarding the site of policy change, the multiple streams theory tends to focus on policy problems and solutions produced for a particular organisation, such as a state or regional organisation with the authority and resources to implement change. Throughout this research, the authors noted that physical inactivity rhetoric does not fit into this neat understanding of policy change, due to both the diaspora of implicated organisations and the range of values and meanings ascribed to physical activity. For this study then, the framework was applied with caution, acknowledging that even if there is official government policy change, this may not be sufficient for lobbyists. According to the rhetoric within these various lobby documents, only widespread action by 'everyone' will lead to success. Added to this complexity is that through Moving More, Living More, the UK Government itself was encouraging other organisations to change their policies. Therefore, we do not contend that any particular government policy will signify sufficient policy change by itself.

It would transpire that 2014 was a lively lobby and policy time for physical activity promoters. The APCPA report would eventually become one of four lobby / policy documents to be published that year. Despite both the liveliness of the physical activity community encountered in this research and the calls for radical change, there was also acknowledgment that change might be slow. The time period for this study was chosen to match the finite duration of the APCPA while 


\section{A multiple streams analysis of physical activity advocacy}

acknowledging the unlikeliness of an expedient solution to the physical activity problem. Therefore, this period could be seen as a part of an ongoing policy formalisation. While Kingdon suggests that policy windows only tend to remain open for a short time, it is apparent that the case of physical activity has the potential to become an ongoing policy concern, in the same way that 'environmental sustainability' continues to feature as an issue in many policy realms, with the ongoing possibility of being taken up by willing entrepreneurs and used to stimulate change. In the UK particularly, the 2014 flurry of activity has contributed to Public Health England's (2014) Everybody Active, Every Day policy initiative. There is scope for further research to evaluate first if significant policy change has occurred and second if it will be successful.

Whereas in the past physical activity has often been subsumed within discussions about obesity, it has recently become established as a health concern in its own right. This elevated status means that a far greater number of settings, activities and organisations become possible sites of intervention. Everyone, everywhere could be judged to be either insufficiently or sufficiently active. While this may seem to be fertile ground to implement radical ideas, the problem's ubiquity may contribute to decision makers considering it to be either a task for other organisations to solve, or too difficult to address in a standalone industry or organisation. There is emerging evidence of this lack of "buy in". In 2016, the Lancet medical journal published another series on physical activity, with various authors lamenting the lack of "political commitment and resources" and the difficulty in creating "public policies to promote physical activity that lie outside the health sector" (Das and Horton, 2016, p. 1).We propose here another factor that that hinders radical ideas being implemented. That is, the nature of "radicalism" itself is often 


\section{A multiple streams analysis of physical activity advocacy}

associated with either socially deviant or untested approaches, and this will contribute to both neo-liberal and conservative organisations being unwilling to take action. We suggest this hindrance is worthy of further study.

We recognise that this study was conducted at a specific policy moment, a time when physical activity was attracting significant media and policy attention. This case study approach is not able to survey the entire landscape of physical activity policy nor the entire corpus of lobbyists involved in pushing various agendas. While this approach is useful in examining the relatively public displays of lobbying, a critically oriented "insider" position would shed more valuable light on which ideas are elevated onto the agenda of meetings to start with. Further, (in line with the multiple streams theory, we acknowledge that simply because some story lines are dominant, this does not necessarily translate into increased budget provision. For this to be accomplished, a study would need to examine retrospectively how the intense lobbying in 2014 correlated with resource allocation from central and local governments. This could be examined by considering both the dominant ideas and marginalised ideas. It is clear that the APCPA did reinforce particular ideas about physical activity (such as emphasising young people and sport) while continuing to marginalise other aspects, with scant or no attention given to older adults and people living with chronic conditions.

There is no single policy which would change to categorically signify a 'major shift' as is typically the focus of multiple streams analyses. Amenta (2006) notes that having a large movement may help to get an issue on the public agenda, though it may subsequently make it more difficult for the movement to formulate and rally around specific policy recommendations. Indeed, the fact that in a variety of existing lobby documents there are calls for new 'radical' ideas and 'innovation' highlights the 
lack of certainty around existing and future policies. Policy entrepreneurs will need to determine just how 'innovative' their proposed solutions are. If too modest, there is a risk that the claimed severe costs of physical inactivity will not be addressed; too radical and the ideas may not be written into policy documents, particularly during periods of fiscal constraints. 
A multiple streams analysis of physical activity advocacy

\section{References}

Abma, T.A. (2006). The Practice and Politics of Responsive Evaluation. American Journal of Evaluation, 27(1), 31-43.

All Party Commission on Physical Activity (2013). Terms of reference. Retrieved 20 February 2014, from http://activitycommission.com/about/terms-of-reference/

All Party Commission on Physical Activity (2014). Tackling Physical Inactivity: A Coordinated Approach. Retrieved 20 February 2014, from http://activitycommission.com Amenta, E. (2006). When Movements Matter: The Townsend Plan and the Rise of Social Security. Princeton, NJ: Princeton University Press.

Ayres, M. (2014a). Twitter comment, 11 Feb, 2014. Retrieved 11 February 2014 from www.twitter.com

Ayres, M. (2014b). Sport Oral Evidence Session for the All Party Commission on Physical Activity, 11 February 2014. Palace of Westminster.

Bailey, R., Hillman, C., Arent, S. and Petitpas, A. (2013). Physical Activity: An Underestimated Investment in Human Capital? Journal of Physical Activity and Health, 10, 289-308.

Biddle, S. (2014). Twitter comment, 8 April, 2014. Retrieved 8 April, 2014 from www.twitter.com 


\section{A multiple streams analysis of physical activity advocacy}

Blankenau, J. (2001). The fate of national health insurance in Canada and the United States: A multiple streams explanation. Policy Studies Journal, 29(1): 38-55.

British Broadcasting Corporation, (2011). All-party parliamentary groups. Retrieved 20 February 2014, from

http://news.bbc.co.uk/democracylive/hi/guides/newsid 81000/81876.stm

British Broadcasting Corporation, (2014). Obesity crisis: Future projections 'underestimated'. Retrieved 20 March 2014 from http://www.bbc.co.uk/news/health25708278

Cameron, D. (2014). Comment in Moving More, Living More, The Physical Activity Olympic and Paralympic Legacy for the Nation. Retrieved 20 March 2014 from www.official-documents.gov.uk

Das, P. \& Horton, R. (2012). Rethinking our approach to physical activity. The Lancet, 380, 189-190.

Das, P. \& Horton, R. (2016) Physical activity - time to take it seriously. The Lancet, http://dx.doi.org/10/1016/SO140-6736(16)31070-4

Faulkner, G., McCloy, C., Plotnikoff, R.C. \& Tremblay, M.S. (2011). Relaunching a national social marketing campaign: expectations and challenges for the "new" participation. Health Promotion and Practice, 12: 569-576. 
Grey-Thompson, T. (2014). Education Oral Evidence Session for the All Party Commission on Physical Activity, 29 January 2014. Palace of Westminster.

Guldbrandsson, K., \& Fossum, B. (2009). An exploration of the theoretical concepts policy windows and policy entrepreneurs at the Swedish Public Health Arena. Health Promotion International, 24(4), 434-444.

Gustat, J., Healy, I., Litt, J., Reed, H., Tabak, R. Goins, KV., Bornstein, D., Carnoske, C., Lyn, R. \& Eyler, A. (2013). Lessons in Promoting Active Living: The Collaborative Perspective. Journal of Public Health Management and Practice. 19, S58-S64.

Hallal, P. C., Bauman, A. E., Heath, G. W., Kohl, H. W., Lee, I.-M., \& Pratt, M. (2012). Physical activity: More of the same is not enough. The Lancet, 380, 190-191.

Houlihan, B. (2005) Public Sector Sport Policy: Developing a Framework for Analysis. International Review for the Sociology of Sport, 40(2), 163-185

Insall, P. (2014). Twitter comment, 10 Feb, 2014. Retrieved 10 February 2014 from www.twitter.com

Kahlmeier, S. et al. (2014). A systematic overview of institutions and bodies active in physical activity promotion in Europe. Schweizerische Zeitschrift für Sportmedizin und Sporttraumatologie, 62(2), 13-18. 


\section{A multiple streams analysis of physical activity advocacy}

Kingdon, J.W. (1985). Agendas, Alternatives, and Public Policies. Boston: Little. Brown.

Kohl, H.W., Craig, C.L., Lambert, E.V., et al. for the Lancet Physical Activity Series Working Group (2012). The pandemic of physical inactivity: Global action for public health. The Lancet, 380: 294-305.

Lang, T. and Rayner, G. (2006). Overcoming policy cacophony on obesity: an ecological public health framework for policymakers. Obesity Reviews; 8(Suppl. 1),165-81.

Lee, I.-M., Shiroma, EJ., Lobelo, F., Puska, P., Blair, S.N., Katzmarzyk, PT., for the Lancet Physical Activity Series Working Group. (2012). Effect of physical inactivity on major noncommunicable diseases worldwide: An analysis of burden of disease and life expectancy. The Lancet, 380, 219-229.

Move1Hour (2014a). Move1Hour Physical Activity Campaign. Retrieved 8 June 2014 from https://twitter.com/move1hour

Move1Hour (2014b). 5 Extra Years video advertisement. Retreived 8 June 2014 from https://www.youtube.com/user/Move1Hour/videos

Nike, The American College of Sport Medicine, and the International Council for Sport Science and Physical Education. (2012). Designed To Move: A physical 


\section{A multiple streams analysis of physical activity advocacy}

Activity Action Agenda. Retrieved 24 November 2013 from http://www.designedtomove.org/

Oral evidence. (2014). Health Oral Evidence Session for the All Party Commission on Physical Activity, 15 January 2014. Palace of Westminster.

Pate, R.R., Freedson, P.S., Sallis, J.F., Taylor, WC., Sirard, J. Trost, S.G. \& Dowda, M. (2002). Compliance with Physical Activity Guidelines: Prevalence in a Population of Children and Youth, Annals of Epidemiology, 12(5), 303-308.

Peck, T. (2012). Government lowers the bar to help Coe claim egacy victory. The Independent. Retrieved 10 February 2014 from http://www.independent.co.uk

Piggin, J., (2015). Designed to move? Physical activity lobbying and the politics of productivity. Health Education Journal, 74(1), 16-27.

Public Health England (2014a) Everybody Active, Every Day: An evidence-based approach to physical activity. Public Health England, London: UK.

Public Health England (2014b) Everybody active, every day. The case for taking action now. A resource for MPs. Public Health England, London: UK.

Radcliffe, P. (2014). Education Oral Evidence Session for the All Party Commission on Physical Activity, 29 January 2014. Palace of Westminster. 
Reed, A. (2014). Twitter comment, Retrieved 11 February 2014 from www.twitter.com.

Richards, R., Murdoch, L., Reeder, A.I., \& Amun, Q.T. (2011) Political activity for physical activity: health advocacy for active transport. International Journal of Behavioural Nutrition and Physical Activity, 8, 52. doi: 10.1186/1479-5868-8-52.

Ridde, V. (2009). Policy implementation in an African state: An extension of Kindgon's multiple-streams approach. Public Administration, 87(4), 938-954.

Sallis, J. et al., for the Lancet Physical Activity Series 2 Executive Committee (2016) Progress in physical activity over the Olympic quadrennium, The Lancet. DOI: http://dx.doi.org/10.1016/S0140-6736(16)30581-5

Scott-Elliot, R. (2013). Significantly fewer people now playing sport regularly than before last year's Olympic Games. The Independent. Retrieved 10 February 2014 from http://www.independent.co.uk

Shilton, T. (2006). Advocacy for physical activity-From evidence to influence. IUHPE - Promotion \& Education, 13, 118-126.

Sport England (2014). Record numbers of people playing sport. Retrieved 11 November 2015 from http://www.sportengland.org/mediacentre/news/2014/june/12/record-numbers-of-people-playing-sport/ 
A multiple streams analysis of physical activity advocacy

Stalker, D. (2014). Foreword, in Turning the Tide of Inactivity. UKActive. Retrieved 10 February 2014 from www.ukactive.com/turningthetide

Stone, D. (2002). Policy paradox: The art of political decision making. New York, NY: W.W. Norton.

UKActive. (2014). Turning the Tide of Inactivity. UKActive. Retrieved 10 February 2014 from www.ukactive.com/turningthetide

UK Government. (2014a). Moving More, Living More, The Physical Activity Olympic and Paralympic Legacy for the Nation. Retrieved 20 March 2014 from www.officialdocuments.gov.uk

UK Government. (2014b). All Party Groups. Retrieved 6 June 2014 from http://www.parliament.uk/about/mps-and-lords/members/apg/

Walt, G., Shiffman, J., Schneider, H. Murray, SF., Brugha, R. \& Gilson, L. (2008). 'Doing' health policy analysis: methodological and conceptual reflections and challenges. Health Policy and Planning, 23, 308-17.

WHO (2016) Physical activity strategy for the WHO European Region 2016-2025. World Health Organisation. 